\title{
Adaptações fisiológicas e anatômicas de Melissa officinalis L. (Lamiaceae) cultivadas sob malhas termorrefletoras em diferentes intensidades luminosas
}

BRANT, R.S. ${ }^{*}$; PINTO, J.E.B.P. ${ }^{2}$; ROSAL, L.F. ${ }^{3}$; ALVES, C. ${ }^{2}$; OLIVEIRA, C. ${ }^{2}$; ALBUQUERQUE, C.J.B. ${ }^{4}$

${ }^{1}$ Embrapa Cocais, Alameda Santos Dumont, 18, Bairro Anil, CEP: 65065-470, São Luís-Brasil *renataplantasmedicinais@yahoo.com.br²Universidade Federal de Lavras, Caixa Postal 3037, CEP: 37200-000, Lavras-Brasil ${ }^{3}$ Instituto Federal de Educação, Ciência e Tecnologia do Pará, Rodovia BR 316, km, 62, Bairro Saudade, CEP: 68740-970, Castanhal-Brasil ${ }^{4}$ Empresa de Pesquisa Agropecuária de Minas Gerais, Unidade Experimental do Triângulo e Alto Paranaíba. Rodovia BR 050, km 63, Bairro Marta Helena, CEP: 38402-019, Uberlândia-Brasil

\begin{abstract}
RESUMO: Objetivou-se, com a realização da pesquisa, avaliar modificações fisiológicas e anatômicas em plantas de melissa, cultivadas sob malhas termorrefletoras (Aluminet $\circledast$ ), em diferentes níveis de sombreamento, visando conhecer a plasticidade fenotípica em resposta de adaptação a diferentes quantidades de luz. Os tratamentos foram caracterizados por plantas submetidas a pleno sol e a 20 e $60 \%$ de intensidade luminosa, e arranjados conforme o delineamento inteiramente casualizado (DIC). As quantificações de clorofila foram feitas em quatro repetições, as medições das epidermes e parênquimas foram repetidas 15 vezes e utilizou-se 10 repetições para as avaliações das características de cloroplastos e grãos de amido destes. Plantas submetidas a 20\% de intensidade luminosa apresentaram maior quantidade de clorofila a e, portanto, maior razão clorofila $a / b$. Comparativamente, as folhas de melissa a pleno sol e a $60 \%$ de luz apresentaram células da epiderme adaxial mais espessas, mas as células da epiderme abaxial mostraram características encontradas em folhas de sombra, ou seja, mais finas. Quanto maior a intensidade luminosa, maior o número de cloroplastos, porém, a pleno sol mostraram-se mais finos e com menor área. Os grãos de amido de plantas cultivadas sob ambientes sombreados tiveram maior área e ocuparam maior parte nos cloroplastos de plantas a $60 \%$ de intensidade luminosa. Assim, plantas de melissa, quando submetidas ao sombreamento, tiveram plasticidade fenotípica.
\end{abstract}

Palavras-chave: plantas medicinais, cloroplasto, epiderme, sombreamento, aluminet

ABSTRACT: Physiological and morphological adaptations of Melissa officinalis L. (Lamiaceae) cultivated under thermo-reflector shading nets at different luminous intensities. The aim of this study was to evaluate physiological and anatomical modifications in lemon balm plants, cultivated under thermo-reflector nets (Aluminet ${ }^{\circledR}$ ) at different levels of shading, in order to understand the phenotypic plasticity in adaptation response to different light quantities. The treatments were characterized by plants subjected to full sun and 20 and $60 \%$ of luminous intensity, and arranged in completely randomized design (CRD). The quantifications of chlorophylls were done in four replicates, the measurements of epidermis and parenchymas were repeated 15 times and 10 replicates were used to evaluate characteristics of chloroplasts and their starch grains. Plants subjected to $20 \%$ of luminous intensity showed higher quantity of chlorophyll $a$ and, therefore, higher chlorophyll $a / b$ ratio. Lemon balm leaves under full sun and $60 \%$ of light showed thicker adaxial epidermis cells, but the abaxial epidermis cells showed characteristics found in shaded leaves, i.e., they were slender. The higher the light intensity, the larger the number of chloroplasts; however, under full sun, they were slender and had smaller area. The starch grains of leaves grown under shaded environments showed larger area and, at $60 \%$ of luminous intensity, occupied the largest part of chloroplasts. Thus, lemon balm plants, subjected to shading conditions, showed phenotypic plasticity.

Key words: medicinal plants, chloroplast, epidermis, shading, aluminet

Recebido para publicação em 08/12/2009

Aceito para publicação em 22/04/2011

Rev. Bras. PI. Med., Botucatu, v.13, n.4, p.467-474, 2011. 


\section{INTRODUÇÃO}

A Melissa officinalis (Lamiaceae) é conhecida no Brasil pelos nomes populares de melissa, ervacidreira, cidrilha e melitéia. É uma erva perene, originária do Sul da Europa, de 30 a $100 \mathrm{~cm}$ de altura, com caule de secção quadrangular, folhas opostas, ovais, denteadas, verde-claras e brilhantes. As flores são branco-amareladas, reunidas em glomérulos axilares. Possui odor semelhante ao do limão e é melífera. Os constituintes químicos principais da planta são o tanino e o óleo essencial, com predominância do citral (Martins et al., 2000).

Preparações com a planta possuem atividade sedativa, tendo um papel importante no controle da ansiedade. É tranquilizante e indutora do sono (Sadraei et al., 2003).

Diferenças nas condições de luminosidade podem acarretar variações nos teores de clorofilas, já que a luz é essencial à síntese deste pigmento (Whatley \& Whatley, 1982). Folhas de sombra, por exemplo, possuem concentração maior de clorofila $\left(\mathrm{mg} \mathrm{g}^{-1}\right)$ do que as folhas de sol (Kramer \& Kozlowski, 1979). Outrossim, a anatomia foliar é altamente especializada para a absorção de luz, e as características do mesofilo, principalmente as do parênquima paliçádico, garantem a absorção uniforme da luz através da folha. De acordo com Taiz \& Zeiger (2004), em geral as folhas de sol são mais espessas e apresentam células paliçádicas mais longas do que as de sombra.

Castro et al. (2007), estudando plantas de Mikania glomerata Sprengel (Asteraceae) sob diferentes níveis de sombreamento, observou que a epiderme foi mais espessa em condições de pleno sol.

Nery et al. (2007), trabalhando com Sombrite $\AA$ a 0, 30, 50 e $70 \%$ de sombreamento com a Calophyllum brasiliense Camb. (Clusiaceae), concluíram que não houve diferença para número de cloroplastos por célula, o qual variou de seis a sete. Todos os tratamentos apresentaram grãos de amido, tendo a $70 \%$ de sombreamento mostrado maior irregularidade morfológica.

No que tange ao cultivo protegido, as telas de sombreamento têm sido empregadas, principalmente, como solução de menor custo econômico, visando níveis adequados de luz. O fabricante afirma que as malhas termorrefletoras, recentemente lançadas no mercado brasileiro, por serem revestidas de alumínio e terem fios retorcidos, fazem com que a temperatura do ambiente abaixe de 10 a $20 \%$, fornecendo, em média, $15 \%$ de luz difusa ao ambiente, não afetando os processos fotossintéticos, promovendo, ainda, o sombreamento.

Existe relação entre a produção dos diferentes metabólitos e os tipos e organização dos tecidos vegetais (Taiz \& Zeiger, 2004). Assim, a obtenção de informações que permitam conhecer o efeito dos tratamentos utilizados nos cultivos das plantas medicinais sobre a estrutura interna dessas plantas é de fundamental importância. Desse modo, as respostas estruturais das espécies são diferenciadas se fazendo necessário conhecê-las para cada qual. Dessa forma, esta pesquisa foi realizada com o objetivo de avaliar modificações fisiológicas e anatômicas em melissa, cultivadas sob malhas termorrefletoras (Aluminet®), em diferentes níveis de sombreamento.

\section{MATERIAL E MÉTODO}

O experimento foi desenvolvido no Horto Medicinal do Departamento de Agricultura (DAG) da Universidade Federal de Lavras (UFLA). O município de Lavras está situado na região Sul do estado de Minas Gerais, a 918,87 metros de altitude, latitude de 2114'S e longitude de 4500'W GRW. De acordo com a classificação climática de Köppen, o clima regional é do tipo Cwa, mas apresenta características de Cwb, com duas estações bem definidas, uma fria e seca, de abril a setembro, e outra quente e úmida, de outubro a março (Brasil, 1992).

Um voucher ou material testemunho da espécie está depositado no Herbário ESAL, do Departamento de Biologia da UFLA e correspondem ao ํo 22155.

As mudas de melissa foram produzidas a partir de uma planta matriz, utilizando-se estacas apicais de cinco centímetros de comprimento e dois $\mathrm{mm}$ de diâmetro e postas para enraizar em bandejas de poliestireno de 128 células, contendo o substrato comercial Plantmax ${ }^{\circledast}$. Foram cultivadas em estufa com $60 \%$ de sombreamento e, posteriormente, aclimatizadas por meio do aumento gradativo da intensidade luminosa.

Sessenta e três mudas foram transplantadas para vasos de $5 \mathrm{~L}$ e colocados nos tratamentos com $20 \%$ de luz (Aluminet $80 \%$ ), $60 \%$ de luz (Aluminet $40 \%$ ) e $100 \%$ de luz (pleno sol) em outubro de 2006.

Os dados climatológicos da cidade de Lavras, MG foram fornecidos pela Estação Climatológica do Departamento de Engenharia Agrícola da UFLA e estão expostos na Tabela 1 e a temperatura média incidente nas plantas de melissa sob $20 \%$ de intensidade luminosa foi de $28^{\circ} \mathrm{C}$, a $60 \%$ de intensidade luminosa foi de $29^{\circ} \mathrm{C}$ e a $100 \%$ de intensidade luminosa foi de $31^{\circ} \mathrm{C}$.

As avaliações foram iniciadas após 13 semanas da instalação do experimento. Folhas do terceiro nó da parte superior da planta foram coletadas ao acaso, em cada tratamento.

As folhas foram imediatamente acondicionadas em papel alumínio e em caixa de isopor com gelo até serem transferidas ao laboratório. A quantificação das clorofilas $a$, be total foi realizada

Rev. Bras. Pl. Med., Botucatu, v.13, n.4, p.467-474, 2011. 
TABELA1. Dados climatológicos da cidade de Lavras, MG, no período de agosto de 2006 a janeiro de 2007.

\begin{tabular}{ccccccc}
\hline Meses/anos & Tmáx & Tmín & Tméd. & Prec. Total & UR & Insol. \\
\hline Agosto/06 & 27,8 & 15,4 & 20,4 & 82,5 & 71,4 & 7,0 \\
Setembro/06 & 27,3 & 13,8 & 19,4 & 73,2 & 65,4 & 7,0 \\
Outubro/06 & 27,3 & 16,9 & 21,2 & 107,0 & 73,9 & 5,2 \\
Novembro/06 & 28,0 & 17,4 & 21,3 & 262,0 & 77,1 & 5,9 \\
Dezembro/06 & 28,5 & 18,7 & 22,8 & 220,6 & 79,1 & 4,8 \\
Janeiro/07 & 27,6 & 18,7 & 22,1 & 554,7 & 87,0 & 3,0 \\
\hline
\end{tabular}

Tmáx- Média mensal da temperatura máxima $\left({ }^{\circ} \mathrm{C}\right)$ Tmín - Média mensal da temperatura mínima (ํㅡ) Tméd - Média mensal de Tmáx e Tmín diárias $\left({ }^{\circ} \mathrm{C}\right)$ Prec. total - Precipitação total mensal (mm) UR - Umidade relativa do ar média mensal (\%) Insol.- Insolação média mensal (horas).

segundo a metodologia de Arnon (1949), utilizandose quatro repetições.

As folhas foram cortadas em pedaços de 1 $\mathrm{cm}$, eliminando-se a nervura central e, em seguida, foram determinadas as massas frescas para cada avaliação (com quatro repetições) e a absorbância das amostras, a $663 \mathrm{~nm}$, para a clorofila a e a 645 $\mathrm{nm}$, para a clorofila $b$, num espectrofotômetro v/uv Beckman modelo $640 \mathrm{~B}$. Os cálculos de mg de clorofila por grama de massa seca de tecido foliar foram realizados a partir das equações: clorofila $a=$ [12,7 x A663 - 2,69 x A645] x [V/(1000xW)]; clorofila $b=[22,9 \times \mathrm{A} 645-4,68 \times \mathrm{A} 663] \times[\mathrm{V} /(1000 \times \mathrm{W})]$; clorofila total $=[20,2 \times A 645+8,02 \times A 663] \times[\mathrm{V} /$ (1000xW)], em que: $A=$ absorbância dos extratos no comprimento de onda indicado; $V=$ volume final do extrato clorofiliano-cetônico; $W=$ massa fresca, em gramas do material vegetal utilizado.

As folhas foram fixadas em FAA 70\% (álcool etílico, formaldeído, ácido acético), por 72 horas e, posteriormente, conservadas em álcool etílico $70 \mathrm{GL}$ (Johansen, 1940).

O exame anatômico das seções transversais foi feito a partir de cortes realizados na região mediana das folhas, incluído em parafina, em micrótomo de mesa rotativo, e submetidos à clarificação em solução de $1 \%$ de hipoclorito de sódio, por 15 minutos. Em seguida, foram lavadas em água destilada, neutralizadas em solução acética a $1 \%$. A coloração com safranina (5\%) e azul de astra (95\%) foi realizada de acordo com os métodos descritos por Bukatsch (1972). Os cortes corados foram montados em lâminas semipermanentes, em glicerina $50 \%$.

As medições da espessura dos tecidos foram realizadas por meio do software de medição Sigma Scan Pro, utilizando-se fotomicrografias registradas em câmera digital Canon PowerShot A620 acoplada ao microscópio KEN-A-VISIONTT18. Foram utilizadas 15 repetições, por tratamento, das características espessura da epiderme nas faces adaxial e abaxial e dos parênquimas paliçádico e esponjoso.

Para a observação da ultraestrutura foliar foram realizadas observações em microscópio eletrônico de transmissão com fragmentos de aproximadamente $0,5 \mathrm{~cm}^{2}$, retirados da porção mediana das folhas que foram fixados em solução de glutaraldeído (2,5\%) e paraformaldeído (2,5\%), em tampão cacodilato, $\mathrm{pH} 7,0 ; 0,05 \mathrm{M}+\mathrm{CaCl}_{2} 0,001 \mathrm{M}$ por, aproximadamente, quatro horas, em temperatura ambiente. Posteriormente, esses fragmentos foram lavados em tampão cacodilato $0,05 \mathrm{M}$ (três vezes de 10 minutos) e pós-fixados em tetróxido de ósmio 1\% em tampão cacodilato $0,05 \mathrm{M}$, por 4 horas. Em seguida, iniciou-se a desidratação em gradiente de acetona (25, 50, 75 e $90 \%$, por 10 minutos e 3 vezes em $100 \%$, por 10 minutos). Logo após, o material foi incluído em gradiente crescente de acetona e resina Spurr $30 \%$, por 8 horas, a $70 \%$, por 12 horas e 2 vezes a $100 \%$, em intervalos de 24 horas. Os tecidos foram emblocados em resina pura e colocados em estufa, a $70^{\circ} \mathrm{C}$, por 48 horas, para a polimerização. Os blocos obtidos foram desbastados com lâminas de aço para a retirada da resina excedente. Foram realizados os cortes em seções semifinas $(1 \mu \mathrm{m}) \mathrm{e}$ ultrafinas $(<100 \mathrm{~nm})$, utilizando-se ultramicrótomo Reichrt-Jung com navalha de diamante.

Os cortes semifinos foram coletados com anel de ouro, colocados em lâminas de vidro, corados com azul de toluidina ( $1 \mathrm{~g}$ de azul de toluidina, $1 \mathrm{~g}$ de borato de sódio e $100 \mathrm{~mL}$ de água purificados por meio de filtro Millipore $0,2 \mu \mathrm{m}$ ) e montados permanentemente em meio Permount. Os cortes ultrafinos foram coletados em grades de ouro (golden 
slot grids) e secos em raques de alumínio cobertos com formvar (Rowley \& Moran, 1975). As seções foram pós-contrastadas em acetato de uranila, seguido por acetato de chumbo, por três minutos cada e, em seguida, examinadas em microscópio eletrônico de transmissão Zeiss, modelo EM 109. Foram utilizadas 10 repetições para cada tratamento e as características observadas para as análises ultraestruturais foram o número de cloroplastos por célula, a área, o comprimento e a largura, a área dos grãos de amido e a proporção relativa da área ocupada pelos grãos de amido nos cloroplastos, em células do parênquima paliçádico.

A análise estatística dos dados obtidos foi realizada pelo programa SISVAR $\AA$ versão 4.3 (Ferreira, 1999), pelo teste de $\mathrm{F}$ e as médias foram comparadas pelo teste de Scott-Knott $(p<0,05)$.

\section{RESULTADO E DISCUSSÃO}

A análise do conteúdo de clorofila revelou variabilidade para clorofila $a$ e a razão $a / b$ entre os tratamentos (Figura 1).

Em plantas de melissa submetidas a $20 \%$ de intensidade de luz, houve o maior teor de clorofila a, porém, não houve diferença entre os demais tratamentos. Pinto et al. (2007) empregaram os mesmos tratamentos desta pesquisa com Aloysia gratissima (Gillies \& Hook.) Tronc. (Verbenaceae) e encontraram resultados semelhantes.

Já para a clorofila $b$, não houve resposta entre os tratamentos, indicando que para melissa, nas condições desta pesquisa, a intensidade luminosa não interferiu na síntese e degradação de clorofila $b$. Pinto et al. (2007) concluíram que o emprego de $20 \%$ de intensidade de luz aumenta o teor de clorofila $b$ em plantas de Aloysia gratissima e a $60 \%$ e $100 \%$ houve semelhança entre si.

Quanto aos teores de clorofila total de melissa, não foi verificada diferença. Pinto et al. (2007) encontraram maiores teores de clorofila total em plantas de Aloysia gratissima cultivadas sob $20 \%$ de intensidade luminosa.

A análise da razão clorofila $a / b$ mostrou que plantas cultivadas sob $20 \%$ de intensidade de luz mostraram valores superiores aos demais tratamentos. Taiz \& Zeiger (2004) afirmam que folhas de sombra têm mais clorofila por centro de reação e a razão clorofila b/clorofila a é mais alta. Consequentemente, a razão $a / b$ é menor em folhas de sombra.

Os resultados da razão clorofila $a / b$ desta pesquisa coincidem com os de Pinto et al. (2007), que verificaram aumento significativo dessa razão com o emprego de $20 \%$ de intensidade de luz em plantas de Aloysia gratissima. Em Mikania glomerata, Castro et al. (2005) constataram que houve diminuição na proporção da clorofila $a / b \mathrm{com} o$ aumento do sombreamento, devido ao incremento da clorofila $b$.

Alguns trabalhos indicam que existe tendência de redução na razão clorofila $a / b$, à medida que se reduz a intensidade de luz (Boardman, 1977; Kozlowski et al., 1991; Scalon et al., 2003). Isto se deve à maior proporção de clorofila $b$ em ambientes sombreados, o que está associado ao fato da degradação ser mais lenta do que a da clorofila $a$ (Engel \& Poggiani, 1991).

As plantas que crescem em ambientes com maior intensidade de luz têm, frequentemente, características estruturais e químicas que aumentam

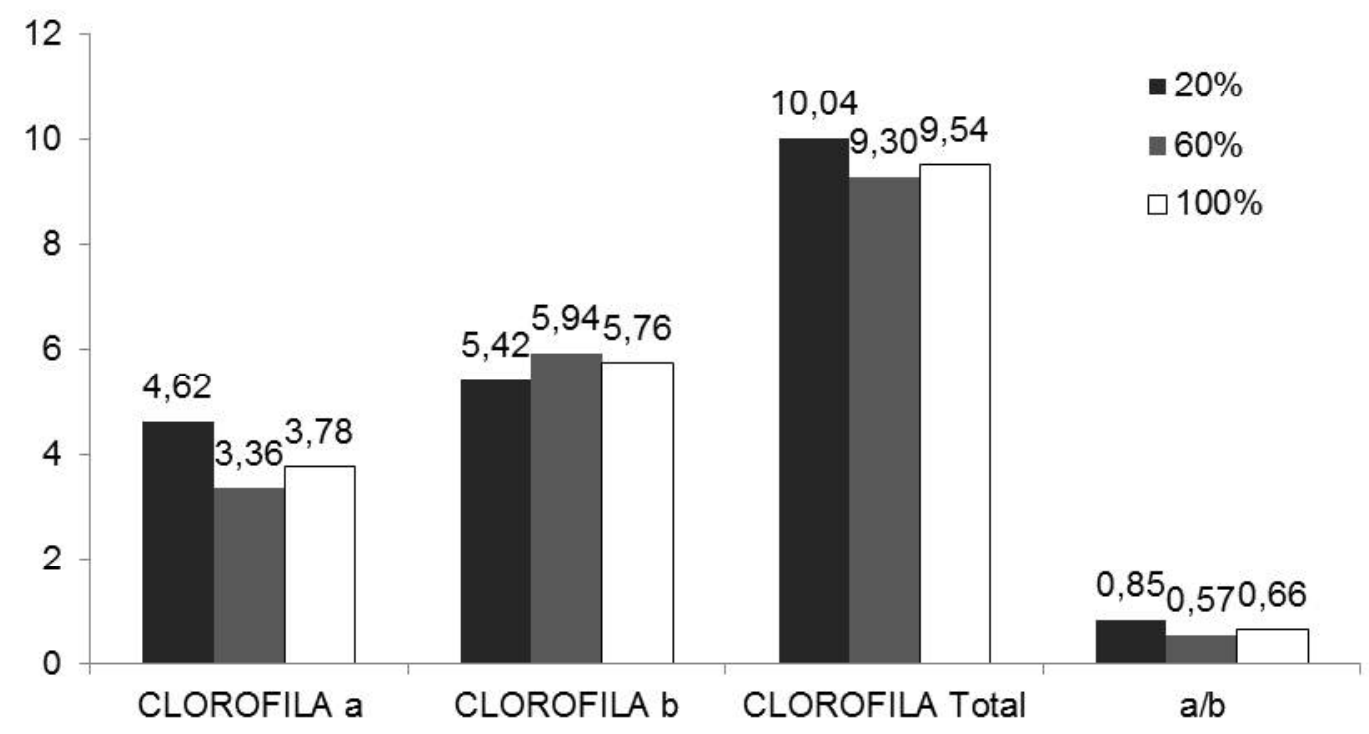

FIGURA 1. Conteúdo de clorofila $a, b$ e total $\left(\mathrm{mg} \mathrm{g}^{-1}\right.$ de massa fresca) e razão clorofila $a / b$ em plantas de Melissa officinalis, cultivadas sob intensidade luminosa de 20,60 e 100\%, com malhas termorrefletoras (Aluminet ${ }^{\circledR}$ ). Médias seguidas pela mesma letra não diferem entre si, pelo teste de Scott-Knott ( $\alpha=5 \%$ ). UFLA, Lavras, MG, 2008. 
a interceptação de luz que alcança o cloroplasto. Além disso, características anatômicas contrastantes podem ser encontradas em folhas da mesma planta expostas a regimes luminosos diferentes (Taiz \& Zeiger, 2004). As análises da espessura da epiderme na face adaxial e do parênquima paliçádico de folhas de melissa submetidas a diferentes intensidades de luz confirmam estas observações (Figura 2).

Com o incremento da intensidade de luz, observa-se aumento significativo na espessura da epiderme na face adaxial de folhas de melissa. Os mesmos resultados foram encontrados por Pinto et al. (2007), ao trabalharem com Aloysia gratissima.

Reportando-se à face abaxial da epiderme, não houve significância entre os tratamentos empregados para melissa.

As células do parênquima paliçádico das folhas de melissa cultivadas a pleno sol e a $60 \%$ de intensidade de luz apresentaram maior espessura que o tratamento de $20 \%$ de intensidade luminosa. Em

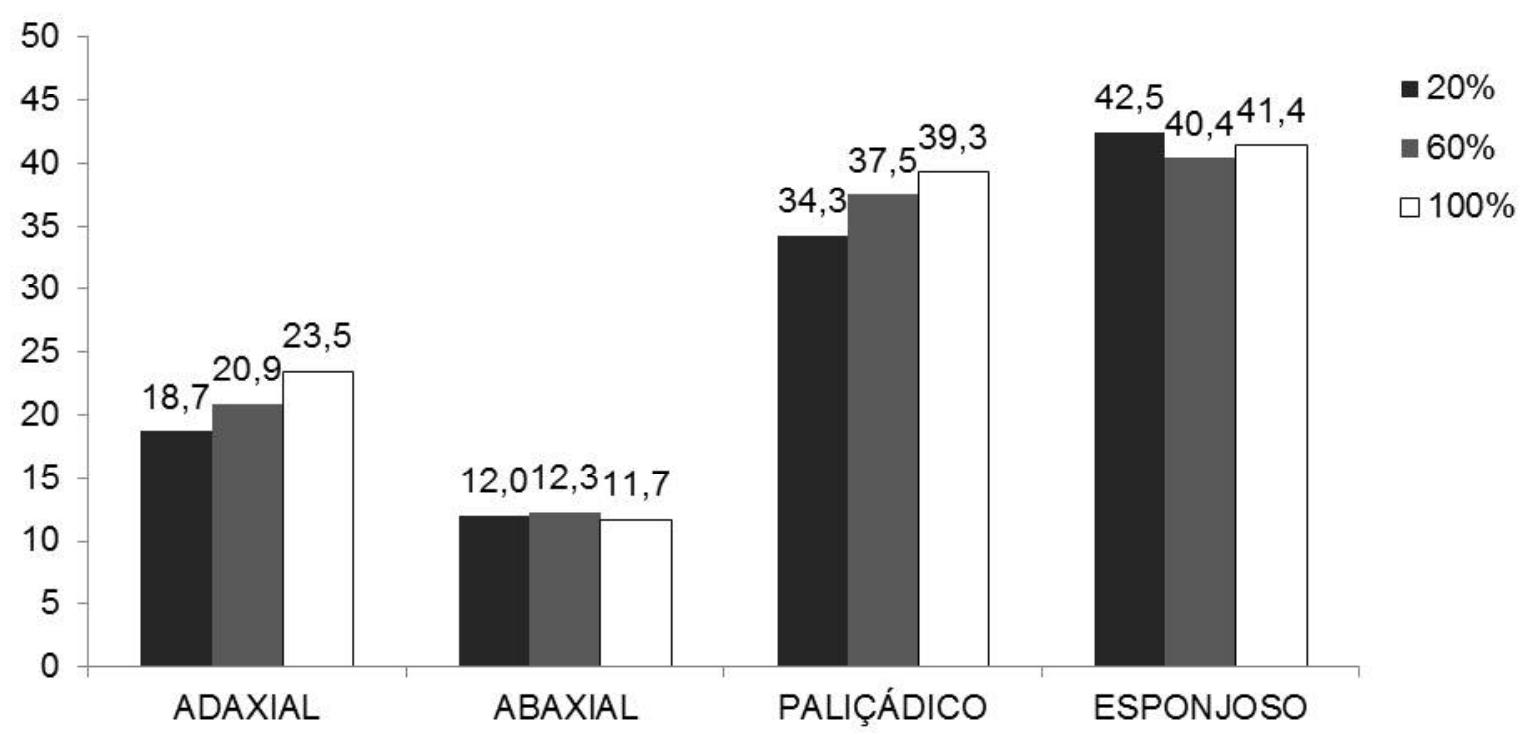

FIGURA 2. Espessura $(\mu \mathrm{m})$ da epiderme nas faces adaxial e abaxial, do parênquima paliçádico e esponjoso de folhas de Melissa officinalis, cultivadas sob intensidade luminosa de 20, 60 e 100\%, com malhas termorrefletoras (Aluminet $\left.{ }^{\circledR}\right)$. Médias seguidas pela mesma letra não diferem entre si, pelo teste de Scott-Knott $(\alpha=5 \%)$.

Aloysia gratissima, Pinto et al. (2007) verificaram aumento progressivo dos parênquimas paliçádico e esponjoso, com o aumento da intensidade luminosa (Figura 2). No entanto, para melissa, a espessura do parênquima esponjoso não apresentou diferença.

De acordo com Taiz \& Zeiger (2004), mesmo partes distintas de uma folha mostram adaptações ao seu microambiente luminoso. As células na superfície superior da folha, expostas ao fluxo fotônico mais alto, caracterizam folhas crescendo à plena luz do sol; as células na superfície inferior têm características encontradas em folhas de sombra. Assim, pode-se inferir que as em folhas de melissa submetidas a maiores intensidades de luz (60\% e 100\%), as células da epiderme na face adaxial e do parênquima paliçádico tiveram características de folhas crescendo à plena luz do sol, e as células da superfície inferior (do parênquima esponjoso e da epiderme na face abaxial) apresentaram as características encontradas em folhas de sombra.

De acordo com Taiz \& Zeiger (2004), as folhas possuem característica adaptativa que pode alterar 0 posicionamento dos cloroplastos, a fim de controlar a absorção de luz e prevenir o dano causado pelo excesso de luz. A ultra-estrutura dos cloroplastos de lâminas foliares de melissa é mostrada na Figura 3.

Dessa forma, em plantas de melissa, podese observar que ocorreram alterações no número, na área e largura dos cloroplastos do parênquima paliçádico de acordo com a intensidade luminosa (Figura 4). Já para Calophyllum brasiliense a 0, 30, 50 , e $70 \%$, mantidas sob sombrite ${ }^{\circledR}$, não houve diferença no número de cloroplasto (Nery et al., 2007).

Já Costa et al. (2007), estudando Ocimum selloi submetidas ao cultivo sob malhas coloridas, observaram que o número de cloroplastos por célula do parênquima paliçádico, bem como o tamanho, foi maior nos tratamentos sombreados.

Apesar de estarem presentes em maior número, foi observada menor área e largura dos cloroplastos de folhas de melissa cultivadas a pleno sol, porém, o comprimento apresentou semelhança entre os tratamentos. De acordo com Taiz \& Zeiger (2004), sob luz fraca, os cloroplastos acumulam-se paralelamente ao plano da folha, de modo que ficam alinhados perpendicularmente à luz incidente - posição que maximiza a absorção de luz. Sob luz forte, os 


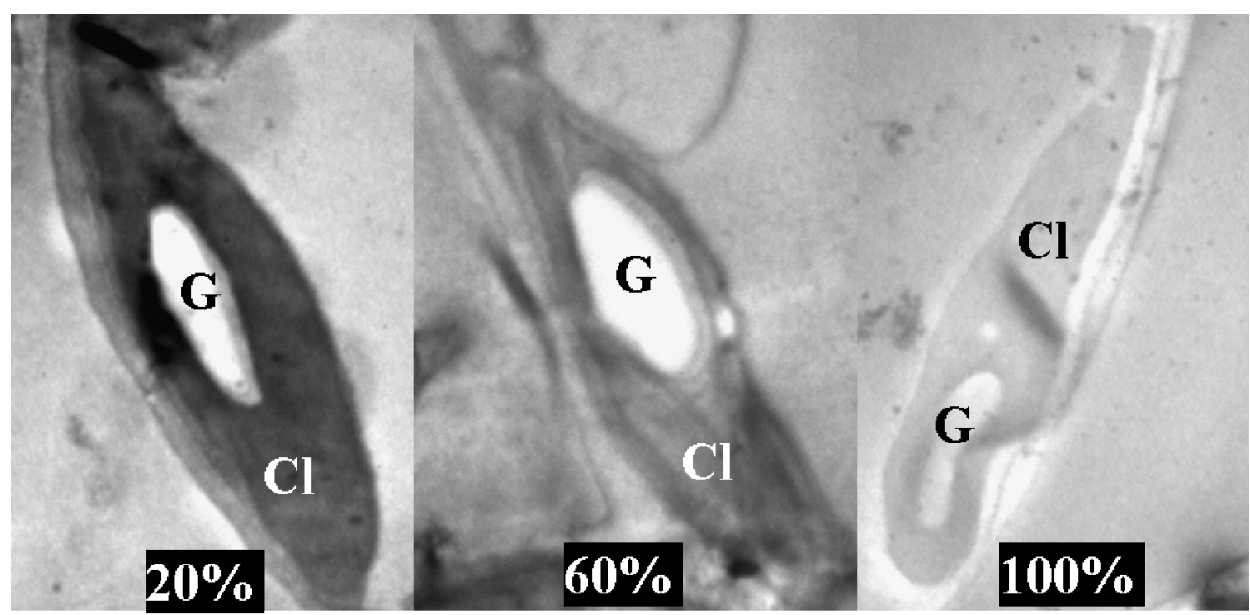

FIGURA 3. Eletromicrografias de transmissão eletrônica (MET) mostrando cloroplastos e grãos de amido nas células do parênquima paliçádico de lâminas foliares de Melissa officinalis, cultivadas sob intensidade luminosa de 20, 60 e 100\%, com malhas termorrefletoras (Aluminet ${ }^{\circledR}$ ). CL- cloroplasto, G- grão de amido, P- parede celular. Escala $=2 \mu \mathrm{m}$.

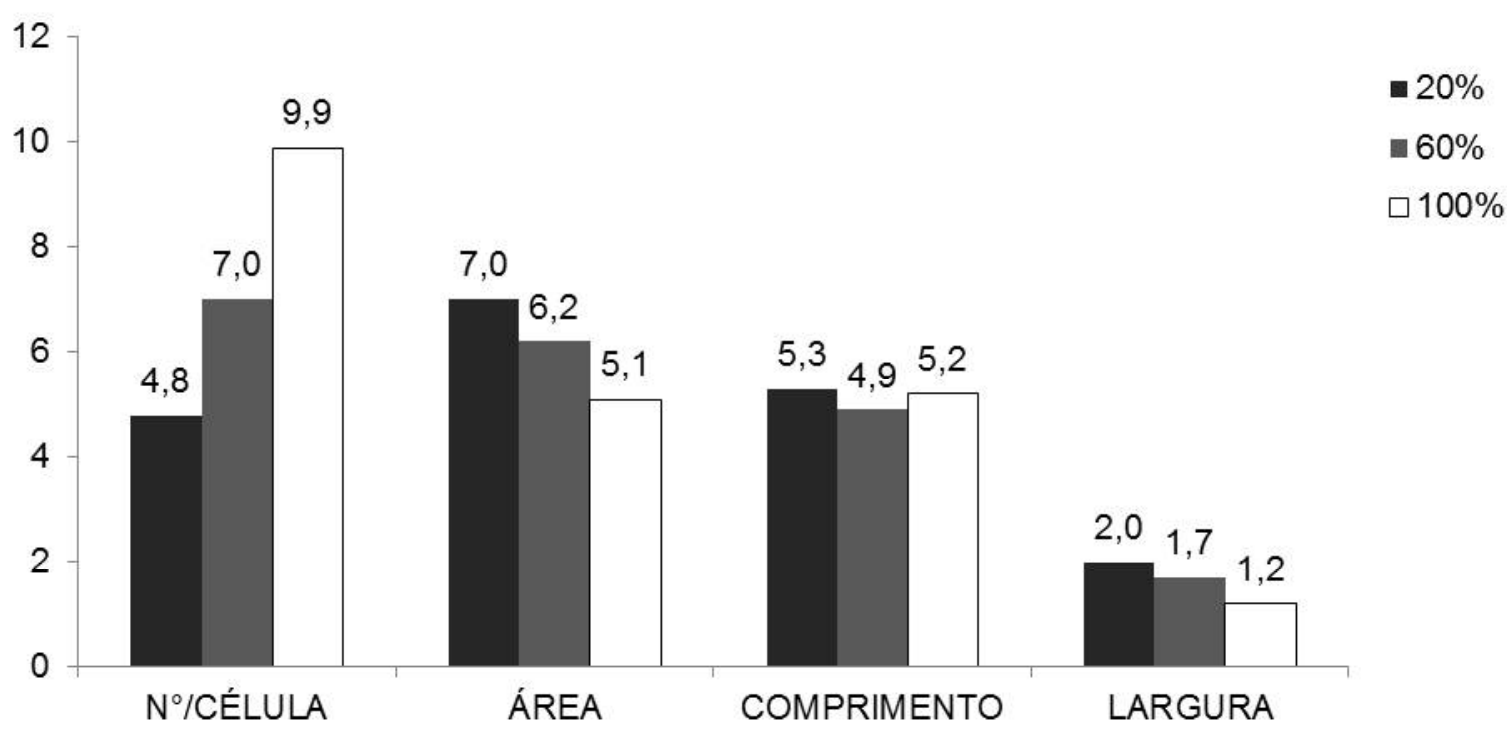

FIGURA 4. Número de cloroplastos por célula, área $\left(\mu \mathrm{m}^{2}\right)$, comprimento $(\mu \mathrm{m})$ e largura $(\mu \mathrm{m})$ de cloroplastos de plantas de Melissa officinalis, cultivadas sob intensidade luminosa de 20,60 e 100\%, com malhas termorrefletoras (Aluminet ${ }^{\circledR}$ ). Médias seguidas pela mesma letra não diferem entre si, pelo teste de Scott-Knott $(\alpha=5 \%)$. UFLA, Lavras, MG, 2008.

cloroplastos movem-se para as superfícies celulares paralelas à luz incidente, de modo a evitar a absorção em excesso. Provavelmente, as folhas de melissa submetidas a pleno sol produziram cloroplastos mais finos como plasticidade fenotípica e, assim, com menor densidade, têm maior mobilidade para responder às variações de luz que ocorrem durante o dia.

No cloroplasto ocorre a síntese dos grãos de amido e estes apresentaram área maior em plantas de melissa cultivadas sob $60 \%$ de intensidade luminosa, em detrimento das demais. Em seguida, plantas sob $20 \%$ de luz apresentaram grãos de amido com área superior à das plantas cultivadas a $60 \%$ e este, maior que em plantas cultivadas a pleno sol (Figura 5).

Quanto à percentagem de ocupação dos grãos de amido nos cloroplastos de parênquima paliçádico de folhas de melissa, plantas submetidas a $60 \%$ de intensidade de luz apresentaram valor médio superior aos demais, que não diferiram entre si.

De modo geral, pode-se concluir que plantas de melissa submetidas a $20 \%$ de intensidade luminosa apresentaram maior quantidade de clorofila a e, portanto, maior razão clorofila $a / b$.

As folhas de melissa cultivada a pleno sol e a $60 \%$ de intensidade de luz apresentaram células mais espessas na epiderme adaxial, enquanto as 

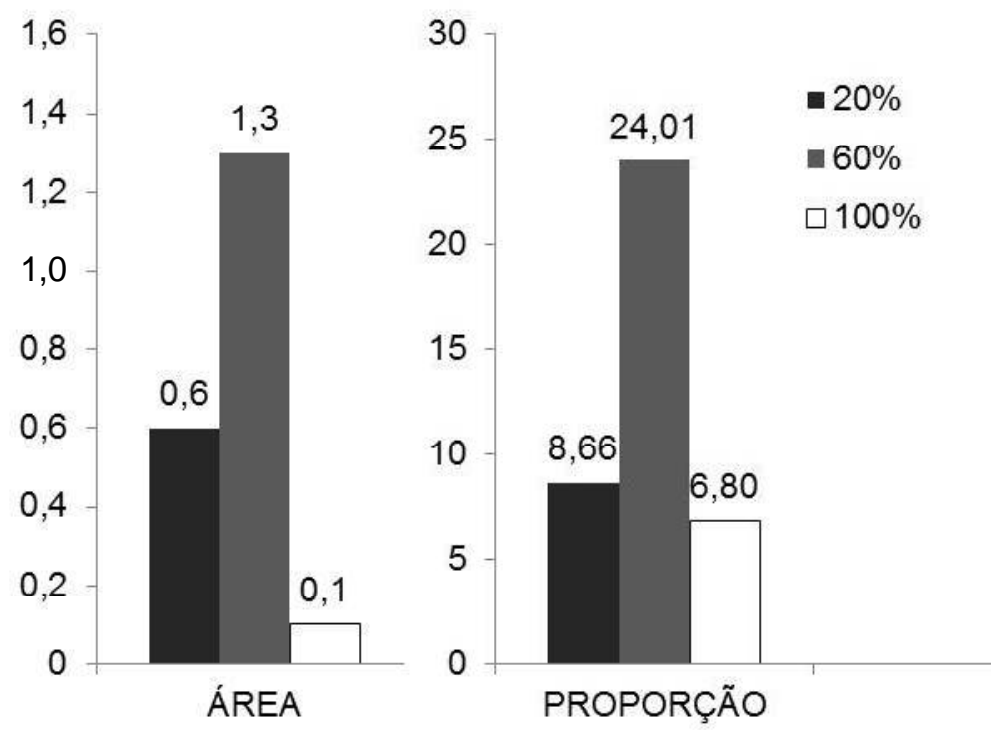

FIGURA 5. Área dos grãos de amido $\left(\mu \mathrm{m}^{2}\right)$ e proporção dos grãos de amido em relação aos cloroplastos (\%) de plantas de Melissa officinalis, cultivadas sob intensidade luminosa de 20,60 e 100\%, com malhas termorrefletoras (Aluminet $\left.{ }^{\circledR}\right)$. Médias seguidas pela mesma letra não diferem entre si, pelo teste de Scott-Knott $(\alpha=5 \%)$.

TABELA 2. Quadro comparativo dos resultados obtidos de conteúdo de clorofila $a, b$ e total (mg g-1 de massa fresca), razão clorofila $a / b$, espessura $(\mu \mathrm{m})$ da epiderme nas faces adaxial e abaxial, do parênquima paliçádico e esponjoso de folhas, número de cloroplastos por célula, área $\left(\mu \mathrm{m}^{2}\right)$, comprimento $(\mu \mathrm{m})$ e largura $(\mu \mathrm{m})$ de cloroplastos, área dos grãos de amido ( $\mu \mathrm{m}^{2}$ ) e proporção dos grãos de amido em relação aos cloroplastos (\%).

\begin{tabular}{lccc}
\hline & $20 \%$ & $60 \%$ & $100 \%$ \\
\hline Clorofila a & Maior & Igual & Igual \\
Clorofila b & Sem variação & Sem variação & Sem variação \\
Clorofila total & Sem variação & Sem variação & Sem variação \\
Relação a/b & Maior & Igual & Igual \\
Adaxial & Menor & Intermediário & Maior \\
Abaxial & Igual & Igual & Igual \\
Paliçádico & Menor & Igual & Igual \\
Esponjoso & Igual & Igual & Igual \\
No/célula & Menor & Intermediário & Maior \\
Área cloroplasto & Igual & Igual & Menor \\
Comprimento & Igual & Igual & Igual \\
Largura & Igual & Igual & Menor \\
Área amido & Menor & Maior & Intermediário \\
Proporção amido & Igual & Maior & Igual \\
\hline
\end{tabular}

células da superfície inferior mostraram características encontradas em folhas de sombra, ou seja, mais finas. Quanto maior a intensidade luminosa, maior o número de cloroplastos, porém, a pleno sol, eles mostraram-se mais finos e com menor área. Os grãos de amido de plantas cultivadas a $60 \%$ de intensidade luminosa tiveram maior área e ocuparam maior parte nos cloroplastos.

Desta forma, plantas de melissa apresentaram adaptações fenotípicas quando submetidas a diferentes quantidades de luz (Tabela 2).

\section{AGRADECIMENTO}

Os autores agradecem CAPES, CNPq e FAPEMIG pela concessão das bolsas de estudo e apoio financeiro.

\section{REFERÊNCIA}

ARNON, D.I. Copper enzymes in isolates choroplasts. Polyphenoloxidade in Beta vulgaris. Plant Physiology, v.24, n.1, p.1-15, 1949. 
BOARDMAN, N.K. Comparative photosynthesis of sun and shade plants. Annual Review of Plant Physiology, v.28, p.355-77, 1977.

BRASIL. Ministério da Agricultura e Reforma Agrária. Normas climatológicas de 1961- 1990. Brasília, 1992. $84 p$.

BUKATSCH, F. Bemerkungen zur Doppelfärbung Astrablau-Safranin. Microkosmos, v.61, n.8, p.255, 1972. CASTRO, E.M. et al. Adaptações anatômicas de folhas de Mikania glomerata Sprengel (Asteraceae), em três regiões distintas da planta, em diferentes níveis de sombreamento. Revista Brasileira de Plantas Medicinais, v.9, n.2, p.8-16, 2007.

CASTRO, E.M. et al. Aspectos anatômicos e fisiológicos de plantas de guaco submetidas a fotoperíodos. Horticultura Brasileira, v.23, n.3, p.846-50, 2005.

COSTA, L.C.B. et al. Aspectos da anatomia foliar de Ocimum selloi Benth. (Lamiaceae) em diferentes condições de qualidade de luz. Revista Brasileira de Biociências, v.5, p.6-8, 2007.

ENGEL, V.L.; POGGIANI, F. Estudo da concentração de clorofila nas folhas e seu espectro de absorção de luz em função do sombreamento em mudas de quatro espécies florestais nativas. Revista Brasileira de Fisiologia Vegetal, v.3, p.39-45, 1991.

FERREIRA, D.F. SISVAR 4. 3-Sistema de analises estatísticas. Lavras: UFLA, 1999.

JOHANSEN, D.A. Plant microtechnique. New York: McGraw-Hill, 1940. 523p.
KOZLOWSKI, T.T.; KRAMER, P.J.; PALLARDY, S.G. The physiological ecology of woody plants. London: Academic, 1991. 657p.

KRAMER, P.J.; KOSLOWSKI, T.T. Physiology of woody plants. New York: Academic, 1979. 811p.

MARTINS, E.R. et al. Plantas medicinais. Viçosa: UFV, 2000. 220p.

NERY, F.C. et al. Aspectos anatômicos de folhas de plantas jovens de Clophyllum brasiliense Cambess. submetidas a diferentes níveis de sombreamento. Revista Brasileira de Biociências, v.5, p.129-31, 2007. PINTO, J.E.B.P. et al. Aspectos morfofisiológicos e conteúdo de óleo essencial de plantas de alfazema-doBrasil em função de níveis de sombreamento. Horticultura Brasileira, v.25, n.2, p.210-4, 2007.

ROWLEY, C.R.; MORAN, D.T. A simple procedure for mounting wrinkle free section on formvar-coated slot grids. Ultramicrotomy, v.1, n.2, p.151-5, 1975.

SADRAEY, H.; GHANNADI, A.; MALEKSHAHI, K. Relaxant effect of essential oil of Melissa officinalis and citral on a rat ileum contractions. Fitoterapia, v.74, p.445-52, 2003. SCALON, S.P.Q. et al. Crescimento inicial de mudas de Bombacopsis glabra (Pasq.) A. Robyns sob condição de sombreamento. Revista Árvore, v.27, n.6, p.753-8, 2003.

TAIZ, L.; ZEIGER, E. Fisiologia vegetal. 3.ed. Porto Alegre: Artmed, 2004. 820p.

WHATLEY, J.M.; WHATLEY, F.R. A luz e a vida das plantas. São Paulo: Universidade de São Paulo, 1982. 101p. 